\title{
Correction to: The Contribution of the European School Of Oncology Education to the Central Asian and Caucasian Regions
}

\author{
Nicholas Pavlidis $^{1}$ (1) - Alisher Kahharov ${ }^{2}$ - Fedro A. Peccatori ${ }^{3,4}$ - Matti Aapro ${ }^{3,5} \cdot$ Alex Eniu $^{1,6}$. Elie Rassy ${ }^{7}$. \\ Franco Cavalli ${ }^{3,8} \cdot$ Alberto Costa $^{3}$
}

Published online: 28 October 2021

(c) American Association for Cancer Education 2021

\section{Correction to: Journal of Cancer Education}

https://doi.org/10.1007/s13187-021-02072-5

The original version of this article unfortunately contained a mistake. The name of the author Matti Aapro is now corrected in the author group.

The original article has been corrected.

Publisher's Note Springer Nature remains neutral with regard to jurisdictional claims in published maps and institutional affiliations.

The original article can be found online at https://doi.org/10.1007/ s13187-021-02072-5.

Nicholas Pavlidis npavlid@uoi.gr

1 European School of Oncology College (ESCO), Milan, Italy

2 Tashkent State Dental Institute, Tashkent, Uzbekistan

3 European School of Oncology, Milan, Italy

4 Gynecologic Oncology Department, European Institute of Oncology IRCCS, Milan, Italy

5 Breast Center, Genolier Cancer Center, Genolier, Switzerland

6 Hospital Riviera Chablais, Rennaz, Switzerland

7 Cancer Medicine Department, Gustave Roussy, 94800 Villejuif, France

8 Oncology Institute of Southern Switzerland, Bellinzona, Switzerland 